\title{
Differential Expression of SLC25A38 Gene in Patients of Acute Lymphoblastic Leukemia
}

\author{
Pritam Prakash ${ }^{1}$, Santosh Kumar ${ }^{2}$, Sanjay Kumar ${ }^{3}$, Shraddha Raj ${ }^{4}$, Poonam Sinha ${ }^{5}$
}

\begin{abstract}
SLC25A38 gene produces a protein that belongs to the mitochondrial solute carrier family, SLC25. It is implicated in apoptotic pathways, which regulate intrinsic caspase-dependent apoptosis. The present study evaluates the expression of the SLC25A38 gene in acute lymphoblastic leukemia (ALL) patients. Among 30 leukemia patients, 25 were adult males and 5 were adult females. An average of 5.3-fold high expression of SLC25A38 gene among the ALL patients that was normalized to GAPDH relative to normal healthy volunteer was observed. There was a direct positive correlation between blast cell abundance and level of expression $(r=0.408, p=0.025)$. The expression level was found to be associated with the proportion of blast cells in the bone marrow. The present results show that expression of SLC25A38 is a common feature in ALL and may be a novel biomarker for prognosis and diagnosis, as well as a potential therapeutic target for ALL.

Keywords: Acute lymphoblastic leukemia, Gene expression, Peripheral blood mononucleotide, Solute carrier $25 \mathrm{~A} 38$.

Indian Journal of Medical Biochemistry (2021): 10.5005/jp-journals-10054-0168
\end{abstract}

\section{INTRODUCTION}

Acute lymphoblastic leukemia (ALL) is a disease characterized by recurrent genetic alteration which causes blockage of the proliferation of precursor $B$ and $T$ cells leading to abnormal cell proliferation and survival. ${ }^{1}$ This hematological malignancy causes the accumulation of abnormal lymphocytes in the bone marrow and peripheral cells. There is extramedullary leukocytosis of various organs such as lymph nodes, central nervous system, and in the thymus as a mediastinal mass. ${ }^{2}$ Acute lymphoblastic leukemia has bimodal age presentation. It accounts for $15-25 \%$ of all adult acute leukemia. Prognosis in older individuals is poor and the overall survival rate is $33-35 \%$ in middle-aged adults and about $30 \%$ in adults over 60 years of age. ${ }^{3-5}$ Five-year survival rate of ALL is about $90 \%{ }^{6,7}$ in children and $75-85 \%$ in adults. ${ }^{8}$

Because of advancing molecular and cytogenetic methods in >than $80 \%$ of cases of ALL, genetic alteration has been seen. These abnormalities influence the prognostic and therapeutic approach used for the treatment of ALL. ${ }^{9}$ With the advent of advanced molecular technology, it is found that these genetic aberrations include chromosomal translocation, mutations, and aneuploidies in the gene responsible for cell cycle regulation of lymphocytes. ${ }^{10}$

SLC 25 is a member of the solute carrier (SLC) family of membrane transport proteins. SLC25 gene is a nuclear gene that encodes mitochondrial carrier protein, localized in the inner mitochondrial membrane, and functions as a transporter of various nucleotide, cofactor, and inorganic ions. ${ }^{11}$ This protein has six alphahelical membrane-spanning domains. ${ }^{12}$ They are synthesized in the cytosol and translocated to the mitochondrial inner membrane where it acts as a transporter between mitochondria and cytosol. ${ }^{11}$ SLC $5 A 38$ belongs to SLC 25 gene superfamily which is located on chromosome number $3 \mathrm{p} 22$. $^{11}$

A mitochondrial transporter protein is coded by this gene which functions as a glycine/5-aminolevulinic acid (ALA) transporter across the inner mitochondrial membrane. So, it is required in erythropoiesis. ${ }^{13-15}$ This gene is abundantly expressed in the liver in an embryonic period which suggests its role in hematopoiesis. ${ }^{16} \mathrm{It}$
1,2,5 Department of Biochemistry, Indira Gandhi Institute of Medical Sciences, Patna, Bihar, India

${ }^{3}$ Department of Microbiology, Nalanda Medical College and Hospital, Patna, Bihar, India

${ }^{4}$ Department of Radiation Oncology, Indira Gandhi Institute of Medical Sciences, Patna, Bihar, India

Corresponding Author: Santosh Kumar, Department of Biochemistry, Indira Gandhi Institute of Medical Sciences, Patna, Bihar, India, Phone: +91 7717794976, e-mail: santoshjik6@gmail.com

How to cite this article: Prakash P, Kumar S, Kumar S, et al. Differential Expression of SLC25A38 Gene in Patients of Acute Lymphoblastic Leukemia. Indian J Med Biochem 2021;25(1):5-8.

Source of support: Nil

Conflict of interest: None

is also demonstrated that $S L C 25 A 38$ is highly expressed in erythroid cells. ${ }^{17}$

Therefore, we hypothesized that the SLC25A38 protein may be significant in the pathological changes associated with leukemia. To further clarify the significance of SLC25A38 protein expression in ALL, samples were collected from patients with different types of lymphoblastic leukemia, and the abnormal expression of the SLC25A38 gene was observed.

\section{Materials and Methods}

\section{Patients and Samples}

The patients included in the study were newly case diagnosed with ALL by cytological examination, peripheral blood, and bone marrow aspirates analysis. A total of 30 patients with ALL and 10 healthy control were included in the study. After taking written consent from all the participants, $5 \mathrm{~mL}$ blood was taken in an EDTA test tube.

\section{PBMC Separation}

$2.5 \mathrm{~mL}$ of FICOLL Plaque was taken in a $15 \mathrm{~mL}$ conical tube $0.5 \mathrm{~mL}$ blood was mixed with $5 \mathrm{~mL}$ PBS to make a 1:1 mixture. The 
blood-PBS mixture was layered gently over the FICOLL Plaque and was centrifuged for 30 minutes at $400 \mathrm{~g}$ with brakes off. The layer in-between the upper and lower layer was carefully drawn with the help of a pipette. The extracted clear layer was centrifuged, pelleted, and washed with PBS twice. For control, blood of 10 healthy volunteers was pooled and then processed.

\section{RNA Isolation from PBMC}

The RNA was extracted from the pelleted PBMC using a QiagenRNeasy kit after counting the number of cells using a hemocytometer. $1 \times 10^{6}$ PBMC cells were shredded with Qia shredder column and then processed according to the protocol with a spin column for RNA isolation. $10 \mu \mathrm{L}$ of DNase treatment with $70 \mu \mathrm{L}$ RDD buffer was done on the lysate before loading it into the spin column. A260/280 of the extracted RNA was measured on a Nanodrop spectrophotometer and was found to be around 2. The average concentration of all extracted RNA was around $100 \mathrm{ng} / \mu \mathrm{L}$. A260/230 ratio was on average $>2$.

\section{cDNA Synthesis}

All the reaction mix components were kept on ice. Mix, and then briefly centrifuge to collect contents to the bottom of the tube before adding to a $0.2 \mathrm{~mL}$ tube. To the tube $4 \mu \mathrm{L} q S c r i p t$ DNA Super Mix (5X), Quantabio, USA (final concentration 1X); 300 ng total RNA and RNase/DNase-free water was added to adjust the total volume of reaction to $20 \mu \mathrm{L}$. After sealing each reaction was vortex gently to mix contents and centrifuged briefly to collect components at the bottom of the reaction tube. The reaction mix was incubated in the thermocycler for 5 minutes at $25^{\circ} \mathrm{C}$ then 30 minutes at $42^{\circ} \mathrm{C}$ and finally 5 minutes at $85^{\circ} \mathrm{C}$. Thereafter holding the reaction mix at $4^{\circ} \mathrm{C}$ until use.

\section{PCR Amplification}

Amplification of SLC25A38 and GAPDH was carried out in different wells in the same run. Each run was carried out in triplicate and variation $>0.99 \mathrm{Ct}$ was discarded. The amplification protocol of both the genes was the same as follows.

SLC25A38 gene was amplified using forward primer 5'-AAGACGCGCTATGAGAGTGG-3', reverse primer 5'-GTAGTCCAT AGTCCATGAGGCAC-3'. Similarly, the GAPDH gene was amplified using forward primer 5'-ACAACTTTGGTATCGTGGAAGG-3', reverse primer 5'-GCCATCACGCCACAGTTTC-3'.

The qPCR reactions were run in a total volume of $25 \mu \mathrm{L}$ with $5 \mu \mathrm{L}$ cDNA using $12.5 \mu \mathrm{L}, 2 \times$ SYBR Green (Applied Biosystems, Thermofisher, USA) $1 \mu \mathrm{L}$ of forward and reverse primer (10 $\mu \mathrm{M})$ each and rest nuclease-free water. The amplification was performed under the following conditions; initial denaturation $95^{\circ} \mathrm{C}$ for 10 minutes followed by 40 cycles of denaturation at $95^{\circ} \mathrm{C}$ for 15 seconds, annealing at $59^{\circ} \mathrm{C}$ for 1 minute. The amplification efficiency of GAPDH as a normalizing gene was evaluated and turn out to be $99.3 \%$. The amplified product was also analyzed on $2 \%$ agarose gel which was 197 and 101 bp for SLC25A38 and GAPDH, respectively (Fig. 1).

\section{Gene Expression Analysis}

The SLC25A38 gene expression in ALL patients normalized to GAPDH relative to normal healthy control was analyzed (Table 1). We used $2^{-\Delta \Delta \mathrm{Cq}}$ method ${ }^{18}$ for analysis of gene expression as our amplification efficiency was close to $100 \%$.

\section{Results}

A total of 30 patients with ALL were enrolled in our study. The mean age of patients was 23 years with a male to female ratio of 2.5:1. Ten normal volunteers were enrolled as the control group. Their age ranged from 20-55 years, with a median value of 26 . They were seven males (70\%), three females (30\%). Other clinical presentations and hematological findings have been listed in Tables 2 and 3.

We observed a mean of 5.3-fold expression of the SLC25A38 gene normalized to GAPDH relative to normal healthy volunteers among the ALL patients (Table 1). Maximum expression up to sevenfold was observed in some subjects (Fig. 2).

There was a direct positive correlation between blast cell abundance and level of expression ( $r=0.408, p=0.025)$, with increasing blast cells the expression of the SLC25A38 gene increases (Fig. 3).

\section{Discussion}

SLC25A38, a solute carrier protein of mitochondria whose role has not been elucidated, is found to be overexpressed in ALL. In the present study, gene for SLC25A38 has 5.3 times overexpressed normalized to GAPDH relative to healthy volunteers. Chen et al. found a high expression of SLC25A38 protein in patients of ALL. He also found high expression of this gene in four different cell lines of ALL. Additionally, he also found that it was overexpressed both in adults $(15 / 32,46.9 \%)$ and pediatric patients $(7 / 23,30.4 \%) .{ }^{19}$ In our study, we also found a positive correlation between blast cell

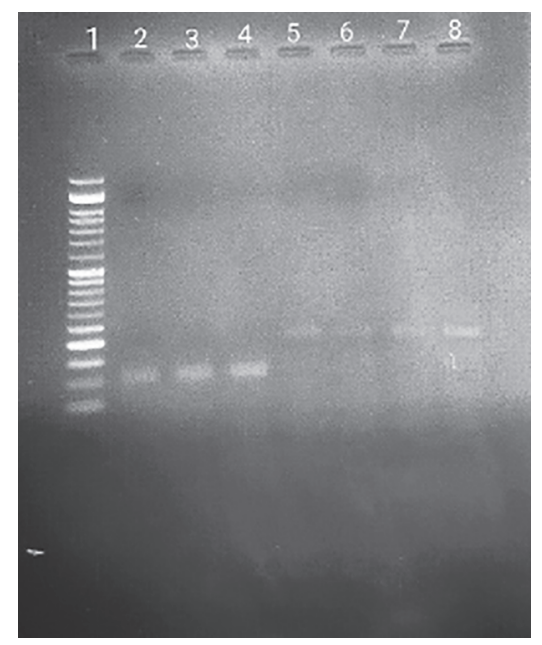

Fig. 1: The amplified product of GAPDH $101 \mathrm{bp}$ and SLC25A38 $197 \mathrm{bp}$ lane $2,3,4$ and $5,6,7,8$, respectively

Table 1: The average Ct value of SLC25A38 gene and GAPDH gene

\begin{tabular}{|c|c|c|c|c|c|}
\hline & SLC25A38 Avg Ct & GAPDH Avg Ct & $\Delta C t$ & $\Delta \Delta C t$ & $\begin{array}{l}\text { Normalized expres- } \\
\text { sion relative to control } \\
2^{-\Delta \Delta C t}\end{array}$ \\
\hline ALL patients & $27 \pm 0.12$ & $22.7 \pm 0.07$ & $4.3 \pm 0.19$ & $-2.4 \pm 0.19$ & 5.3 \\
\hline Control & $30.1 \pm 0.21$ & $23.4 \pm 0.16$ & $6.7 \pm 0.2$ & $0.00 \pm 0.2$ & 1.0 \\
\hline
\end{tabular}


abundance and level of expression (Fig. 3). A possible reason for this may be because a mitochondrial transporter protein is coded by this gene which functions as a glycine/ALA transporter across the inner mitochondrial membrane. So, it is required in erythropoiesis. ${ }^{13-15}$ This gene is abundantly expressed in the liver in the embryonic period which suggests its role in hematopoiesis. ${ }^{16}$ It is also demonstrated that SLC25A38 is highly expressed in erythroid cells. ${ }^{17}$ But such high expression in other cells of myeloid and lymphoid origin as indicated by the findings need to be investigated.

In ALL, various genetic alterations are resulting in uncontrolled clonal proliferation of lymphoblast. ${ }^{20-23}$ The outcome of ALL has now been improved due to combinational chemotherapy, but some subtypes have a poor prognosis and many of the patients are

Table 2: Summary of clinical presentation of the 30 ALL patients

\begin{tabular}{|c|c|c|c|}
\hline \multicolumn{2}{|c|}{ Parameter } & \multirow{2}{*}{$\begin{array}{l}\text { Number of ALL } \\
\text { patients } \\
25\end{array}$} & \multirow{2}{*}{$\frac{\text { Percentage }}{83.3}$} \\
\hline Sex & Male & & \\
\hline & Female & 5 & 16.7 \\
\hline \multirow{2}{*}{$\begin{array}{l}\text { Lymphadenop- } \\
\text { athy }\end{array}$} & Present & 19 & 63.3 \\
\hline & Absent & 11 & 36.7 \\
\hline \multirow[t]{2}{*}{ Splenomegaly } & Present & 22 & 73.3 \\
\hline & Absent & 8 & 26.7 \\
\hline \multirow[t]{2}{*}{ Hepatomegaly } & Present & 23 & 76.7 \\
\hline & Absent & 7 & 23.3 \\
\hline \multirow[t]{2}{*}{ Fever } & Present & 25 & 83.3 \\
\hline & Absent & 5 & 16.7 \\
\hline Pallor & Present & 30 & 100.0 \\
\hline
\end{tabular}

Table 3: Summary of laboratory data of the 30 ALL patients at diagnosis

\begin{tabular}{ll}
\hline Parameters & Median (range) \\
\hline WBCs $1 \times 10^{3} / \mu \mathrm{L}$ & $23.1(2.7-97.7)$ \\
Hemoglobin $\mathrm{g} / \mathrm{dL}$ & $8.7(4.1-11.4)$ \\
Platelets $1 \times 10^{3}$ & $110(45-230)$ \\
PB blasts\% & $37(22-60)$ \\
BM blasts\% & $66(45-87)$ \\
\hline
\end{tabular}

WBCs, white blood cell count; $\mathrm{PB}$, peripheral blood; $\mathrm{BM}$, bone marrow resistant to chemotherapy and some of them experience relapse. Gene inhibitors and micro-RNA regulation give promising results in these situations. ${ }^{24-26}$ Although several studies have been done on sideroblastic anemia and SLC25A38, very few studies have been conducted on lymphoid or myeloid cancer. An unusual overexpression in ALL is indicating an underlying mechanism that may be connected to the proliferation of lymphoblastic tumor cells. Since the blast cell abundance was positively correlated to the expression level of protein, estimating the expression level of the gene may be of prognostic value. From our study, it can be hypothesized that overexpression of the SLC25A38 gene is connected with ALL.

\section{Conclusion}

Overexpression of the SLC25A38 gene is observed in patients of ALL. So, the determination of this gene expression is paving a promising way for gene targeting treatment of ALL. As the sample size is small further studies are required to establish SLC gene expression analysis as a molecular target of ALL treatment and the role of this gene in the regulation of proliferation differentiation and apoptosis of leukemic cells.

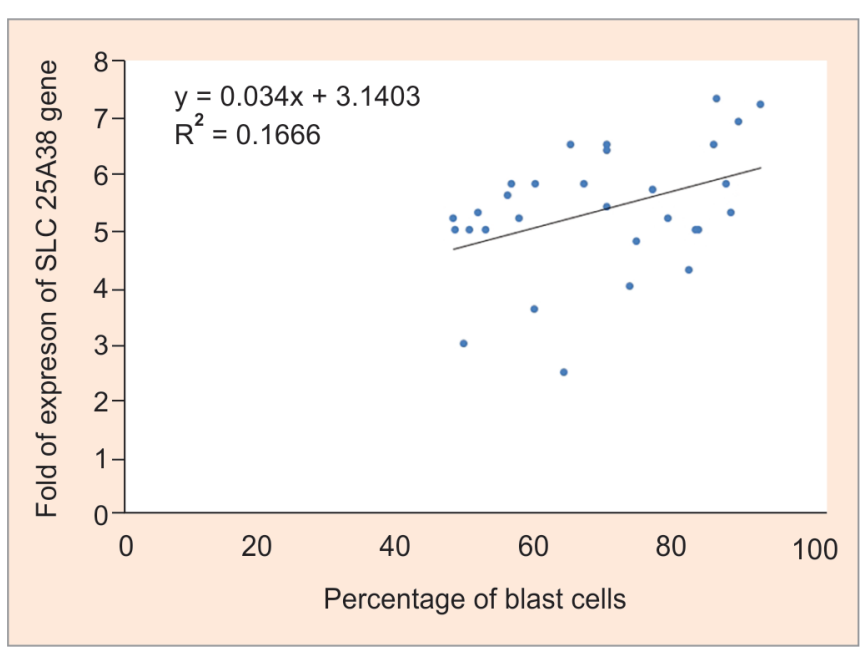

Fig. 3: Correlation between the level of SLC25A38 gene expression and blast cell abundance

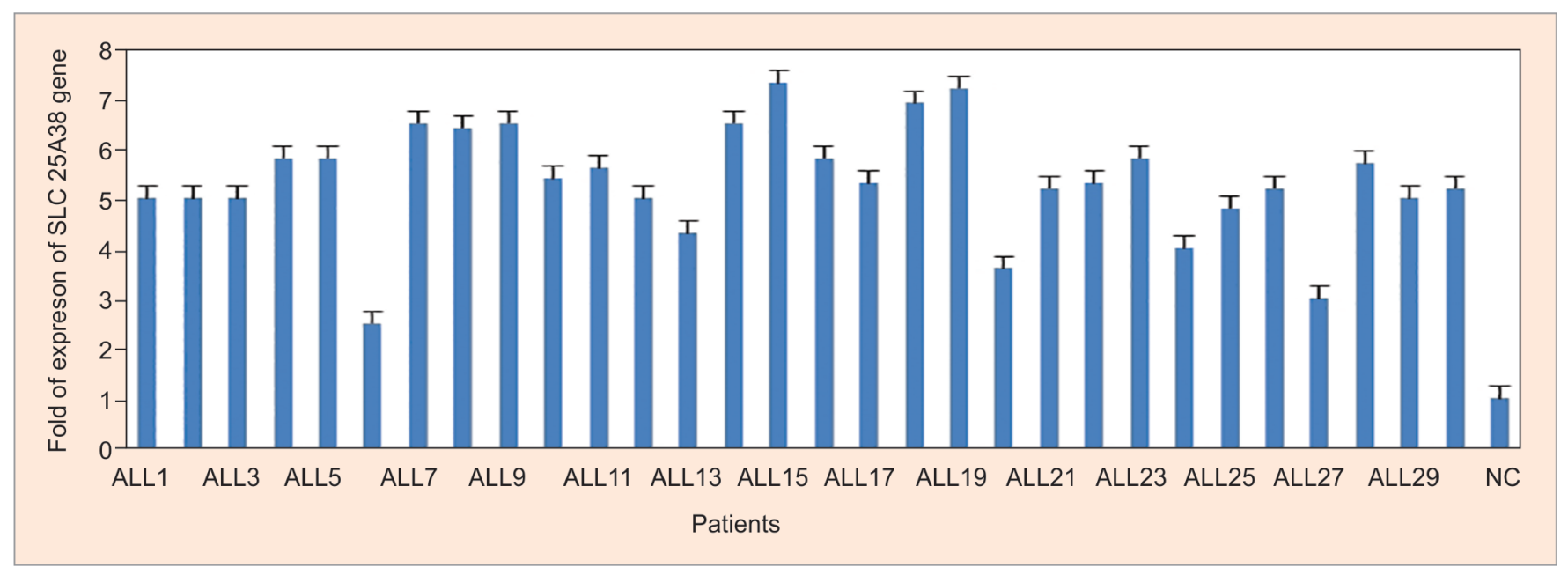

Fig. 2: Expression of SLC25A38 gene normalized to GAPDH relative to healthy control 


\section{Ethical Permission}

This study was approved by the Institutional Review Board Research Ethics Committee of IGIMS, Patna letter no 809/IEC/2019/IGIMS. It has been performed in accordance with the ethical standards laid down in the 1964 Declaration of Helsinki.

\section{References}

1. Belver $L$, Ferrando $A$. The genetics and mechanisms of $T$ cell acute lymphoblastic leukaemia. Nat Rev Cancer 2016;16(8):494. DOI: 10.1038/nrc.2016.63.

2. Hales EC, Taub JW, Matherly LH. New insights into Notch1 regulation of the PI3K-AKT-mTOR1 signaling axis: Targeted therapy of $\gamma$-secretase inhibitor resistant T-cell acute lymphoblastic leukemia. Cellul Signal 2014;26(1):149-161. DOI: 10.1016/j.cellsig.2013.09.021.

3. Faderl S, O'Brien S, Pui C-H, et al. Adult acute lymphoblastic leukemia: Concepts and strategies. Cancer 2010;116(5):1165-1176. DOI: 10.1002/ cncr.24862.

4. Gökbuget N, Kneba M, Raff T, et al. Adult patients with acute lymphoblastic leukemia and molecular failure display a poor prognosis and are candidates for stem cell transplantation and targeted therapies. Blood 2012;120(9):1868-1876. DOI: 10.1182/blood2011-09-377713.

5. Korfi K, Smith M, Swan J, et al. BIM mediates synergistic killing of B-cell acute lymphoblastic leukemia cells by BCL-2 and MEK inhibitors. Cell Death Dis 2016;7(4):e2177. DOI: 10.1038/cddis.2016.70.

6. Santiago R, Vairy S, Sinnett D, et al. Novel therapy for childhood acute lymphoblastic leukemia. Expert Opin Pharmacother 2017;18(11):10811099. DOI: 10.1080/14656566.2017.1340938.

7. Linabery AM, Ross JA. Trends in childhood cancer incidence in the U.S. (1992-2004). Cancer 2008;112(2):416-432. DOI: 10.1002/cncr.23169.

8. Smith MA, Seibel NL, Altekruse SF, et al. Outcomes for children and adolescents with cancer: Challenges for the twenty-first century. J Clin Oncol 2010;28(15):2625-2634. DOI: 10.1200/JCO.2009.27.0421.

9. Eulàlia G, Jordi R, Josep-Maria R. Acute lymphoblastic leukemia of T progenitors: from biology to clinics. Med Clin 2015;144(5):223-229. DOI: 10.1016/j.medcli.2014.01.029.

10. Hunger SP, Mullighan CG. Acute lymphoblastic leukemia in children. N Engl J Med 2015;373(16):1541-1552. DOI: 10.1056/NEJMra1400972.

11. Palmieri $F$, Monné M. Discoveries, metabolic roles and diseases of mitochondrial carriers: a review. Biochim Biophys Acta 2016;1863(10):2362-2378. DOI: 10.1016/j.bbamcr.2016.03.007.

12. Zhang $Y$, Zhang $Y$, Sun $K$, et al. The SLC transporter in nutrient and metabolic sensing, regulation, and drug development. J Mol Cell Biol 2019;11(1):1-13. DOI: 10.1093/jmcb/mjy052.

13. Guernsey DL, Jiang $\mathrm{H}$, Campagna DR, et al. Mutations in mitochondrial carrier family gene SLC25A38 cause nonsyndromic autosomal recessive congenital sideroblastic anemia. Nat Genet 2009;41(6):651653. DOI: $10.1038 / \mathrm{ng} .359$.

14. Bergmann AK, Campagna DR, Mcloughlin EM, et al. Systematic molecular genetic analysis of congenital sideroblastic anemia: evidence for genetic heterogeneity and identification of novel mutations. Pediatr Blood Cancer 2010;54(2):273-278. DOI: 10.1002/ pbc.22244.

15. Kannengiesser C, Sanchez M, Sweeney M, et al. Missense SLC25A38 variations play an important role in autosomal recessive inherited sideroblastic anemia. Haematoligica 2011;96(6):808-813. DOI: 10.3324/haematol.2010.039164.

16. Zhang $\mathrm{H}$, Zhang $\mathrm{Y}, \mathrm{Chen} \mathrm{Y}$, et al. Appoptosin is a novel pro-apoptotic protein and mediates cell death in neurodegeneration. J Neurosci 2012;32(44):15565-15576. DOI: 10.1523/JNEUROSCI.3668-12.2012.

17. Hediger MA, Romero MF, Peng JB, et al. The ABCs of solute carriers: physiological, pathological and therapeutic implications of human membrane transport proteins. Pflugers Arch 2004;447(5):465-468. DOI: 10.1007/s00424-003-1192-y.

18. Livak KJ, Schmittgen TD. Analysis of relative gene expression data using real-time quantitative PCR and the 2(-Delta DeltaC(T)) method. Methods 2001;25(4):402-408. DOI: 10.1006/meth.2001.1262.

19. Chen $H, L u Q$, Zhang $Y$, et al. Overexpression of SLC25A38 protein on acute lymphoblastic leukemia cells. Oncol Lett 2014;7(5):1422-1426. DOI: $10.3892 / 01.2014 .1947$.

20. Ferrando AA, Look AT. Clinical implications of recurring chromosomal and associated molecular abnormalities in acute lymphoblastic leukemia. Semin Hematol 2000;37(4):381-395. DOI: 10.1016/s00371963(00)90018-0.

21. Ferrando AA, Neuberg DS, Staunton J, et al. Gene expression signatures define novel oncogenic pathways in T cell acute lymphoblastic leukemia. Cancer Cell 2002;1(1):75-87. DOI: 10.1016/ s1535-6108(02)00018-1.

22. Soulier J, Clappier E, Cayuela JM, et al. HOXA genes are included in genetic and biologic networks defining human acute T-cell leukemia (T-ALL). Blood 2005;106(1):274-286. DOI: 10.1182/blood-2004-103900.

23. Ferrando AA, Armstrong SA, Neuberg DS, et al. Gene expression signatures in MLL-rearranged T-lineage and B-precursor acute leukemias: dominance of HOX dysregulation. Blood 2003;102(1):262268. DOI: 10.1182/blood-2002-10-3221.

24. Budhu A, Ji J, Wang XW. The clinical potential of microRNAs. J Hematol Oncol 2010;3(1):37. DOI: 10.1186/1756-8722-3-37.

25. Fernando TR, Rodriguez-Malave NI, Rao DS. MicroRNAs in B cell development and malignancy. J Hematol Oncol 2012;5(1):7. DOI: 10.1186/1756-8722-5-7.

26. Whitehead KA, Langer R, Anderson DG. Knocking down barriers: advances in siRNA delivery. Nat Rev Drug Discov 2009;8(2):129-138. DOI: $10.1038 / \mathrm{nrd} 2742$. 